\title{
Pervasive Upper Mantle Melting beneath the Western US
}

\author{
Saswata Hier-Majumder ${ }^{\mathrm{a}}$, Benoit Tauzin ${ }^{\mathrm{b}}$ \\ ${ }^{a}$ Department of Earth Sciences, Royal Holloway University of London, Egham, Surrey, \\ TW20 OEX, UK. \\ ${ }^{b}$ Laboratoire de Géologie de Lyon, Terre, Planètes, Environnement, Université de Lyon, \\ Ecole Normale Supérieure de Lyon, CNRS UMR 5276, 2 rue Raphael Dubois, 69622 \\ Villeurbanne Cedex, France.
}

\begin{abstract}
We report from converted seismic waves, a pervasive seismically anomalous layer above the transition zone beneath the western US. The layer, characterized by an average shear wave speed reduction of $1.6 \%$, spans over an area of $\sim 1.8 \times 10^{6} \mathrm{~km}^{2}$ with thicknesses varying between 25 to $70 \mathrm{~km}$. The location of the layer correlates with the present location of a segment of the Farallon plate. This spatial correlation and the sharp seismic signal atop of the layer indicate that the layer is caused by compositional heterogeneity. Analysis of the seismic signature reveals that the compositional heterogeneity can be ascribed to a small volume of partial melt $(0.5 \pm 0.2 \mathrm{vol} \%$ on average). This article presents the first high resolution map of the melt present within the layer. Despite spatial variations in temperature, the calculated melt volume fraction correlates strongly with the amplitude of P-S conversion throughout the region. Comparing the values of temperature calculated from the seismic signal with available petrological constraints, we infer that melting in
\end{abstract}

Email address: Saswata.Hier-Majumder@rhul.ac.uk (Saswata Hier-Majumder) 
the layer is caused by release of volatiles from the subducted Farallon slab. This partially molten zone beneath the Western US can sequester at least $1.2 \times 10^{17} \mathrm{~kg}$ of volatiles, and can act as a large regional reservoir of volatile species such as $\mathrm{H}$ or $\mathrm{C}$.

Keywords: Transition zone; Mantle Melting; Volatile Cycle; Seismic Anomaly, LVL

\section{Introduction}

The mantle transition zone plays a unique role in controlling the Earth's 3 volatile cycle. Nominally anhydrous silicate minerals in the transition zone 4 can dissolve substantially larger quantities of $\mathrm{H}$ in their crystal structure, 5 compared to the major mantle minerals above and below (Bolfan-Casanova, 6 2002; Kohlstedt et al., 1996). The gradient in H solubility across the transi7 tion zone has been posited as a source for volatile-induced melting atop and 8 below the transition zone in regions of upwelling or downwelling (Bercovici 9 and Karato, 2003; Schmandt et al., 2014). In addition, a recent study of melt10 ing of slab carbonates suggests that carbonate phases in subducting slabs can lead to the generation of carbonatitic melts near the base of the upper man- 
thermal anomalies that can have diffuse boundaries. In addition, thickness and spatial extent of the layer, magnitude of seismic wave speed reduction, and spatial correlation with tectonic features such as subduction can provide additional insight into the origin and nature of melting within the layer. Spatial correlation between the partially molten layer and cold regions of the transition zone can indicate the possibility of volatile-induced melting, as the solidus of dry mantle peridotite is likely higher than the temperature within the zone. In studying such partially molten layers, it is crucial to quantify the amount of melt in the layer as the melt content and its spatial variations can provide indirect evidence for processes associated with the origin, transport, and storage of the melt. While a number of previous studies reported the presence of melting atop the transition zone, detailed regional maps of partial melt, derived from seismic observations, still remain scarce.

Several previous studies reported the occurrence of low seismic velocity layers (LVLs) $350 \mathrm{~km}$ below the surface (Courtier and Revenaugh, 2007; Gao et al., 2006; Revenaugh and Sipkin, 1994; Song et al., 2004; Tauzin et al., 2010; Vinnik and Farra, 2007). The sharp reduction of velocity at the onset of the LVL is sometimes referred to as the 350 discontinuity (Vinnik and Farra, 2007). Recent studies suggest that the LVL can be present on a global scale (Tauzin et al., 2010; Vinnik and Farra, 2007), with the distance above the 410 discontinuity changing laterally from $20 \mathrm{~km}$ to as much as $90 \mathrm{~km}$ over a few hundred kilometers. Correlations of these variations with hot (Hier-Majumder et al., 2014; Vinnik and Farra, 2007) or cold (Courtier and Revenaugh, 2007; Hier-Majumder and Courtier, 2011; Song et al., 2004) tectonic environments have remained elusive (Tauzin et al., 2010), suggesting 
that the variations in position cannot be explained by temperature alone.

In the Western US, studies reporting an LVL are based either on P-S receiver functions and P-wave triplication (Song et al., 2004), P-S receiver functions (Fee and Dueker, 2004; Jasbinsek and Dueker, 2007; Jasbinsek et al., 2010; Schmandt et al., 2011), or S-P receiver functions (Vinnik et al., 2010). The LVLs have been found beneath the border between Oregon and Washington (Song et al., 2004), Yellowstone (Fee and Dueker, 2004; Jasbinsek and Dueker, 2007), the northern Rocky Mountains (Jasbinsek and Dueker, 2007), the southern Colorado Plateau and the Rio Grande Rift (Jasbinsek et al., 2010), and under California (Vinnik et al., 2010)(Figure 1a).

Due to the lack of coverage and absence of extensive analysis involving rock physics and melt microstructure, however, these studies were unable to quantify the spatial expanse and local variations in the melt content in the LVL. Using limited coverage underneath the Coral Sea and Hawaii, the LVLs were estimated to contain approximately 1 vol\% melt (Hier-Majumder and Courtier, 2011; Hier-Majumder et al., 2014). The seismic data in these two studies, however, were too sparse to create a detailed regional map of melting. Such detailed regional maps of melting are crucial in understanding the global volatile cycle, as they allow correlation between the structure and geometry of the melt zone and the tectonic environment, potentially identifying processes involved in melt generation, metasomatism, and melt storage.

In this study, we address the issue of a detailed regional map of melting underneath the Western US, using high resolution seismic data. The seismic signature of the LVL was derived from 820 seismometers of the dense 
broad-band US Transportable Array (Figure 1b). We applied the P-to-S receiver function (RF) technique to the records of 932 teleseismic earthquakes giving a set of 65,000 RFs (Tauzin et al., 2013). The RF technique uses compression-to-shear (P-S) converted seismic waves to detect sharp shearwave velocity changes beneath stations. With such a dense seismic array, the RF technique enables the detection of thin layers in the transition zone over a semi-continental scale and with a high lateral resolution.

In the following sections we outline our findings for the Western US. We discuss the methods of analysis of the RF data and the rock physics analysis in Section 2, present our key findings in Section 3, and discuss the implications for the regional volatile cycle in Section 4.

\section{Methods}

\subsection{Receiver function data analysis}

\subsubsection{Data}

In this study, we used 3-component broad-band records of passive seismicity at stations deployed during the US Transportable Array experiment between January 2004 and November 2009 (Tauzin et al., 2013). Waveforms were obtained from the IRIS Data Management Center for 932 teleseismic earthquakes, occurring at depths shallower than $350 \mathrm{~km}$, with epicentral distances between $40^{\circ}$ and $95^{\circ}$, and magnitudes of at least 5.5. These earthquakes were recorded during the two first deployments of the Transportable Array covering the western half of the US at 820 sites (Figure 1b).

To extract the signal of waves converted from P-to-S (P-S) at seismic boundaries beneath the receivers, we built receiver functions (RFs) by de- 
convolving the records of the $\mathrm{P}$-wave rotated along the radial component by the records rotated along the vertical component. The original records are low-pass filtered at $5 \mathrm{~s}$ period, then deconvolved using an iterative time domain deconvolution method (Ligorria and Ammon, 1999). In this deconvolution method, the applied Gaussian function has a width $L=1.125 \mathrm{~s}$ at half the maximum amplitude to respect the vertical resolution of converted waves at TZ depth ( $\lambda / 2$ where $\lambda$ is the wavelength of the shear-wave). Quality control were made, with a selection based on the ratio of the RMS amplitudes of the signal after the P-wave and of the noise before the P-wave (Tauzin et al., 2013). The data set consists of 64,578 RFs and provides a good coverage in P-to-S piercing points at transition zone discontinuities. A precise map of this coverage is shown in the study from Tauzin et al. (2013). This coverage is highlighted by the area that is not shaded in Figures 3 and 4 . The data collected in this study have been obtained from the mobile Transportable Array and do not include the data from the Caltech Regional Seismic Network, explaining a gap in coverage in the extreme South of California (Figures 3 and 4).

\subsubsection{Imaging procedure}

Our imaging procedure is based on common conversion point (CCP) stacking (Tauzin et al., 2013; Wittlinger et al., 2004). Assuming locally horizontal interfaces, rays corresponding to S-legs for P-S conversions are back-propagated with their theoretical azimuth and incidence from each receiver to depth in the mantle. The back-propagation is computed using the IASP91 velocity model (Kennett and Engdahl, 1991) after an Earth flattening transformation (Muller, 1985). For every time sample on the RFs the 
amplitude is projected to its theoretical spatial location along the ray in the 1D medium. The medium is discretized with blocks of $1 \mathrm{~km}$-vertical and $10 \mathrm{~km}$-lateral dimensions. In these blocks, coherent stacking of the energy from RFs of many rays incoming from different directions gives the locations of seismic interfaces. To benefit from data redundancy and increase the signal-to-noise ratio, the CCP amplitudes within a distance from the vertical plane along the profile are projected and averaged onto this plane to obtain a 2D depth-distance CCP section (e.g. Figure 2a). These CCP sections are smoothed using a Gaussian weighting with the length of semi-axes corresponding to the lateral extent of the Fresnel zones of converted waves at transition zone depths (Wittlinger and Farra, 2007).

We constructed two types of seismic sections, dedicated to describe the 2D structure at different length-scales. To obtain a section with high signal ratio, such as in Figure 2, we projected the amplitudes within $\pm 200 \mathrm{~km}$ from the vertical plane along the profile. For building higher resolution maps of the discontinuity structure over the western US, we reduced the lateral extent of projection of the CCP signal to $\pm 100 \mathrm{~km}$ from the vertical plane of the profile (see Tauzin et al., 2013, for details).

The geographical distribution and variation in depths of the major seismic boundaries (the 410, 660 and the LVL) were obtained from picking their signal on 2D CCP seismic sections along orthogonal profiles at intervals of $0.5^{\circ}$ in longitude and latitude. In that case, the distance of projection is \pm 100 $\mathrm{km}$ around the profile. We derived the maps of the interfaces by combining the information provided by the North-South and East-West seismic cross sections (Tauzin et al., 2013). From the picked topography of the 410 and 660 
boundaries, we estimated variations in the TZ thickness from the reference, $\delta h$ (Figure 3a), which is a more robust proxy for the temperature within the TZ than the absolute depth of discontinuities (Tauzin and Ricard, 2014a). We also picked the negative signal associated with the P-S conversion at the top of the LVL (Figure 4a). The depth difference from the 410 discontinuity provides an estimate of the LVL thickness (Figure 4b).

The vertical resolution achieved by the data, i.e. the ability to separate vertically two seismic interfaces, is $\lambda / 2 \approx 10 \mathrm{~km}$, where $\lambda=C T$ is the wavelength of the shear-wave given the minimal period $T$ of the data and $C$ the velocity $(T=5 \mathrm{~s}$ and $C=4.5 \mathrm{~km} / \mathrm{s})$. This vertical resolution ensures the reliable detection of a 20 to $90 \mathrm{~km}$-thick LVL atop the 410 discontinuity (Figure 1a-b). The lateral resolution, given by $\sqrt{\lambda z / \cos ^{2} i_{c}}$ where $z$ is the depth of analysis and $i_{c}$ the incidence angle (Cerveny, 2005; Wittlinger and Farra, 2007), is of the order of $100 \mathrm{~km}$ at transition zone depths. Finally, the maximal vertical extension of a detectable velocity gradient is given by $\lambda_{P} / 4 \approx 10 \mathrm{~km}, \lambda_{P}$ being the P-wavelength (Bostock, 1999).

Along the $\mathrm{A}-\mathrm{A}^{\prime}$ profile, we applied a bootstrap resampling approach (Efron and Tibshirani, 1990) to provide an estimate of the standard errors on the depths and amplitudes of seismic signals. We constructed $N=50$ bootstrap samples by choosing randomly $67 \%$ of the original RF data set and duplicating $33 \%$ of it to complete the data set. We then applied the CCP stacking approach on these $N$ samples to obtain an average seismic section and a standard error on the seismic amplitudes (Figure 2a-b). Clearly, along the $\mathrm{A}-\mathrm{A}^{\prime}$ profile in Figure 2, amplitudes on the RF section are reliable up to the lateral distance of $+500 \mathrm{~km}$ along the profile. Further East, the strongly 
oscillating seismic amplitudes are the result of noise, as demonstrated by the large standard errors in Figure 2b.

We also obtained for the A- $\mathrm{A}^{\prime}$ profile the errors on $\delta h$, the LVL thickness, and P-S conversion amplitudes. We repeated the picking operation over the $N$ bootstrap samples, then measured an average and a standard deviation. Figure 2c-d gives the result of such a picking on the $N$ bootstrap samples (gray lines), the average (solid lines), and the $95 \%$ confidence levels (dashed lines) for the depths and seismic amplitudes of the 410-km discontinuity and the top of the LVL. The temperature distributions obtained from the bootstrap samples of $\delta h$ along the A- $\mathrm{A}^{\prime}$ profile are also shown in Figure 5b.

\subsubsection{Computing the shear-wave velocity in the LVL}

In addition to the depth of interfaces, we are also interested in the seismic shear-wave velocity at $\sim 350 \mathrm{~km}$ depth within the LVL, $V_{S}^{\text {obs }}$. We use the method outlined in Hier-Majumder et al. (2014) to estimate this seismic velocity. In this method, we calculate $V_{S}^{\text {obs }}$ from the P-S conversion amplitudes $A_{P S}$, determined from the transmission coefficients at discontinuities. First, we define the measured amplitude ratio of the conversion at the top of the LVL and at the 410 discontinuity, $R_{\text {norm }}^{L V L}$ as,

$$
R_{\text {norm }}^{L V L}=\frac{A_{P S}^{L V L}}{A_{P S}^{410}} \leq 0 .
$$

The map in Figure 4(c) depicts the distribution of this ratio over the western US. The value of this ratio is plotted with uncertainties for the A- $\mathrm{A}^{\prime}$ profile in Figure 5e.

Variations in the amplitudes of conversion, $A_{P S}^{L V L}$, among sites can result from site specific conditions, and may not necessarily reflect the variations 
caused by properties of the LVL. Using the ratio normalizes this effect, as both amplitudes should be equally influenced by conditions specific to one site. The ratio of the amplitudes is then used to determine the observed shear wave speed atop the LVL from wave-speeds at $410 \mathrm{~km}$ and $350 \mathrm{~km}$ in the PREM model,

$$
V_{S}^{\text {obs }}=V_{S}^{\text {norm }}\left(1-R_{\text {norm }}^{L V L}\right)+V_{S}^{410} R_{\text {norm }}^{L V L}
$$

where $V_{S}^{410}$ and $V_{S}^{\text {norm }}$ are absolute shear-wave speeds from the PREM model (Dziewonski and Anderson, 1981) at the depths of 410 and $350 \mathrm{~km}$, respectively. Notice that $R_{\text {norm }}^{L V L} \leq 0$, thus the calculated $V_{S}^{o b s}$, is not a weighted average of the reference velocities $V_{S}^{\text {norm }}$ and $V_{S}^{410}$ in equation (2). In Section 2.3 , we describe the way this observed shear-wave speed is used to calculate the unknown melt volume fraction at each site. The map in Figure 6(a) depicts the distribution of this velocity, $V_{S}^{\text {obs }}$, over the western US.

\subsection{Temperature calculation}

The temperature of the mantle plays an important role in the seismic signature of the low velocity layer, by controlling the bulk and shear moduli of the solid. Lateral variations in the temperature can trade-off with the signature of the mantle melting. It is, therefore, crucial to account for spatial variations in temperature.

We use the method outlined in Tauzin and Ricard (2014a) to calculate the temperature from the thickness of the TZ below each site of observation of the LVL. This empirical method extracts from the apparent $\delta h$ a relationship between the 410 and 660 Clapeyron slopes, and takes into account in a selfconsistent manner the effect of temperature on boundary topography and 
seismic velocities. The advantage of this approach is that it does not rely on a priori corrections from independent tomographic models.

First, we assume a reference mantle temperature $T_{r e f}$ which corresponds to the top of the transition zone coincident with the global depth of 410 $\mathrm{km}$. Since both olivine polymorph transitions at 410 and $660 \mathrm{~km}$ depths are sensitive to temperature, any deviation of the TZ thickness from a reference thickness indicates a temperature anomaly in the TZ. In the western US, the $\mathrm{TZ}$ is in average $252-\mathrm{km}$ thick and shows $\pm 25 \mathrm{~km}$ lateral variations (Figure 3a). Corresponding temperature variations normally depend on the Clapeyron slopes of the 410 and 660 phase transitions. The seismic analysis of Tauzin and Ricard (2014a) revealed a linear relationship between the Clapeyron slopes $\left(\gamma_{660}=-0.64 \gamma_{410}-1.17\right)$, allowing to parameterize the temperature- $\delta h$ relationship only with one of the Clapeyron slopes. We thus expressed the temperature under each site as,

$$
T=T_{\text {ref }}+\Delta T(\gamma, \delta h)
$$

where $\delta h$ is the TZ thickness variation, $\gamma$ is the Clapeyron slope of the 410 phase transition, and the exact expression of the temperature anomaly $\Delta T(\gamma, \delta h)$ is given by Tauzin and Ricard (2014a). To test the sensitivity of our results to the prescribed Clapeyron slope, we calculated $T$ for 9 different values of $\gamma$ varying between 0.5 to $4.5 \mathrm{MPa} / \mathrm{K}$. In this article, we show the results for a Clapeyron slope of $+3 \mathrm{MPa} / \mathrm{K}$, as suggested by Tauzin and Ricard (2014a). 


\subsection{Rock physics analysis}

Small amounts of partial melting can exert significant influence on the effective physical properties of rocks. The extent of this influence depends on the volume fraction of the melt; geometry of the melt; and physical properties of the solid matrix and the melt, which, in turn, are controlled by temperature and composition of both phases. In this analysis, we use the method outlined in the study of Hier-Majumder et al. (2014).

The principal component of this analysis involves predicting a reference seismic wave speed $V_{S}^{r e f}(T, C)$ based on the composition of the solid reference mantle $C$ and the temperature $T$ at each LVL site. We use the data from Xu et al. (2008), for a bulk composition containing $40 \%$ basaltic component. The map in Figure 6(b) shows the distribution of this velocity, $V_{S}^{r e f}$, in the western US. The variations in $V_{S}^{r e f}$ are primarily caused by the variations in the temperature, as depicted by the map of $\mathrm{TZ}$ thickness variation in Figure 3(a). We also define the melt anomaly function $\xi\left(\theta, \phi, \rho_{m}, \rho_{s}\right)$, which depends on the dihedral angle, $\theta$, densities of the solid and the melt ( $\rho_{s}$ and $\rho_{m}$, respectively), and the unknown melt volume fraction, $\phi$. We then constrain $\xi$ such that $V_{S}^{\text {ref }}$ matches the observed seismic wave speed $V_{S}^{\text {obs }}$, within a preset tolerance, $\epsilon=1 \times 10^{-9}$, such that,

$$
V_{S}^{o b s}-\xi V_{S}^{r e f}=\epsilon
$$

Since $V_{S}^{\text {ref }}$ depends on temperature and solid composition, while $\xi$ depends on melt related parameters, it is useful to define the anomaly $\Delta V_{S}$, which, assuming $\epsilon \approx 0$ in equation (4), is given by 


$$
\Delta V_{s}=\frac{V_{S}^{o b s}-V_{S}^{r e f}}{V_{S}^{r e f}}=\xi-1 .
$$

While the observed amplitude ratio, $R_{N o r m}^{L V L}$ depends on temperature, solid composition, and melting, this anomaly isolates the effect of melting. In the absence of melting, marked by $\xi=1, \Delta V_{S}=0$. In the presence of melting, $\xi>1$, and $\Delta V_{S}<0$.

Using the formulation for $\xi$ prescribed in Hier-Majumder et al. (2014), we can rewrite equation (4) as,

$$
V_{S}^{o b s}-V_{S}^{r e f} \sqrt{\frac{(1-\phi)\left(1-(1-\psi(\theta, \phi))^{n}\right)}{\left(1+\phi\left(1-\frac{\rho_{m}}{\rho_{s}}\right)\right)}}=\epsilon,
$$

where $\psi(\theta, \phi)$ is the dihedral angle and melt fraction dependent contiguity, the fractional area of intergranular contact. The exponent $n$ also depends on the contiguity $\psi$. We use the formulation of von Bargen and Waff (1986), to express contiguity as a function of melt volume fraction for a given dihedral angle. Equation (6) thus becomes a nonlinear, implicit equation in the unknown $\phi$.

We solve the nonlinear equation (6) for $\phi$, using a modified NewtonRaphson method for each of the 583 sites using the numerical model MuMaP (Hier-Majumder et al., 2014). To account for variations in the Clapeyron slope, dihedral angle, and reference potential temperature, we carried out a total of 46,507 analyses over 583 locations. We carried out a series of numerical experiments for 5 different reference mantle temperatures between $1400 \mathrm{~K}$ and $1800 \mathrm{~K}$, in increments of $100 \mathrm{~K}$, and Clapeyron slopes of the olivine-to-wadsleyite phase transition ranging from +0.5 and $+4.5 \mathrm{MPa} / \mathrm{K}$, in increments of $0.5 \mathrm{MPa} / \mathrm{K}$, for a dihedral angle of $25^{\circ}$, resulting in a total 
of 26,235 analyses. In addition, we carried out another set of simulations for the same range of temperatures, a Clapeyron slope of $+3 \mathrm{MPa} / \mathrm{K}$, and 7 values of dihedral angle ranging from $10^{\circ}$ to $40^{\circ}$, in increments of $5^{\circ}$, resulting in another additional 19,822 analyses to study the variation in the calculated melt volume fraction as a function of the dihedral angle. The resulting variation in calculated melt fraction as a function of dihedral angle is plotted in Figure 6(b). The uncertainty in our calculations arising from assumptions about the Clapeyron slope and the dihedral angle is discussed in the following subsection.

Global correlation between petrological and seismic thermometers suggests a negative linear correlation between TZ thickness and mantle potential temperature (Courtier et al., 2007). For the regional average TZ thickness of $252 \mathrm{~km}$ in this study, this correlation yields a reference mantle potential temperature of $1554 \mathrm{~K}$ for the region. In this article, we chose to report the results for a reference mantle temperature of $1600 \mathrm{~K}$, Clapeyron slop of +3 $\mathrm{MPa} / \mathrm{K}$ and a dihedral angle of $25^{\circ}$. Our analyses yield the melt volume fraction for the 583 locations in the region (Figure 7).

\subsection{Uncertainty analysis}

We distinguish two types of uncertainties associated with our results. The first type arises from seismic observations (variations in the transition zone thickness $\delta h$, and the amplitudes of P-S conversions $R_{\text {norm }}^{L V L}$ ), while the second type is associated with the rock physics analysis (the Clapeyron slope $\gamma$, the dihedral angle $\theta$, the bulk mantle composition $C$, the melt density $\rho_{m}$ ). A similar analysis by Hier-Majumder et al. (2014) reveals that the influence of bulk mantle composition and melt density on the predicted melt fraction is 
insignificant. Consequently, we focus on estimating the uncertainty arising from the remaining 4 parameters. This uncertainty can be calculated by numerical propagation of errors.

Propagated numerically, the uncertainty in the final measurement, $\alpha$, can be expressed as a function of uncertainties $\alpha_{i}$ in the values of the parameter $x_{i}\left(x_{i}=\theta, \gamma, \delta h, R\right)$, and the derivative of the average melt fraction with $x_{i}$ as,

$$
\alpha^{2}=\sum_{i} \alpha_{i}^{2}\left\langle\frac{\partial \phi}{\partial x_{i}}\right\rangle_{j \neq i}^{2},
$$

where $\langle q\rangle$ is the arithmetic mean of the quantity $q$. We calculated the derivatives $\left\langle(\partial \phi) /\left(\partial x_{i}\right)\right\rangle$ numerically from the data for each of each of these 4 variables, keeping the other 3 constant, as shown in Supplementary Figure 1. We present the values of the derivatives and the uncertainties in Table 1 in the supplementary material. We use the uncertainty in the Clapeyron slope from a compilation of laboratory measurement by Tauzin and Ricard (2014b). The uncertainty is dihedral angle is relatively poorly constrained. We chose to use a value of $5^{\circ}$, similar to the variations observed in carbonate melt -olivine $\left(25^{\circ}-30^{\circ}\right)$ systems by Minarik and Watson (1995).

Our estimates of the standard errors on seismic parameters have been obtained from bootstrap resampling (see section 2.1.2). We provide the average standard errors $\alpha_{i}$ for the A-A' profile and derivatives $\left\langle\frac{\partial \phi}{\partial x_{i}}\right\rangle_{j \neq i}$ in Table 1 of the supplementary material. Generalizing the bootstrap approach to the whole western US region in a future work will provide a basis for interpreting lateral variations of melt volume fraction given their uncertainties. 


\section{Results}

We report the layer over a region of $\sim 1.8 \times 10^{6} \mathrm{~km}^{2}$ in Western US, below the Cascade Ranges, the Rocky Mountains and Yellowstone caldera, and the topographic lows of the Snake River plain and Columbia plateau (Figure 4a). Given the frequency content of the RF data, the top of the LVL is sharp, characterized by a velocity gradient over a vertical distance smaller than $10 \mathrm{~km}$. As shown on either side of the dashed line in Figure 4b, this interface is located at a height of $42 \pm 6 \mathrm{~km}$ above the transition zone with significant lateral variations, from $45-70 \mathrm{~km}$ in the southwest to $20-35 \mathrm{~km}$ in the northeast. The amplitude of the P-S conversion shown in Figure 4c is an indirect measure of the shear-wave velocity drop of $-0.2 \%$ to $-5 \%$ across the region, with a median value of $-1.6 \%$.

Multiple lines of evidence demonstrate a clear spatial correlation between the LVL and the subducted former Farallon plate. Increased thickness of the transition zone over a large area $\left(\sim 800 \times 1000 \mathrm{~km}^{2}\right)$ west of the NNW-SSE boundary (dashed line in Figure 3a) coupled with the high P-wave velocity (Figures $3 \mathrm{~b}$ and $5 \mathrm{a}$ ) outline the cold slab. In addition, the calculated mantle temperature (Figure 5b) suggests that the transition zone underneath the western side of the Snake River plain is nearly $150 \pm 80 \mathrm{~K}$ colder than the surrounding mantle. In addition, there is a good agreement in this region between tomography models and predicted location of the subducted Farallon plate from flow models constrained by plate motions (e.g. Liu and Stegman, 2011). Therefore, the elongated fast and cold body, stalled within the transition zone from the California-Nevada border to the Snake River plain and Yellowstone region (Figures 3b and 5a), is likely a remnant of the subducted 
Farallon plate.

The LVL is likely caused by compositional anomaly rather than elevated mantle temperature. Overlying the 410 discontinuity, the pervasive negative signal marking the sharp drop in velocity atop the LVL directly overlies the cold slab fragment (Figure 5a, c). The LVL is the thickest and marked by the strongest velocity contrast at a distance of $-250 \mathrm{~km}$ along the profile (Figure $5 \mathrm{~d}-\mathrm{e}$ ), where the transition zone is the coldest (Figure 5b). In addition, the LVL thickness drops gradually as the plate approaches the Yellowstone Caldera and the associated warm plume. At West, where the Farallon-Juan de Fuca plate is the youngest and the temperature is cold $(95 \pm 25 \mathrm{~K}$ below the Basin and Range in Nevada), the LVL is absent (Figs. 4 and 5).

The partially molten region is widespread in spatial extent, marked by a small average amount of $0.5 \pm 0.2 \mathrm{vol} \%$ melt (Figure 7) for a reference mantle temperature of $1600 \mathrm{~K}$. The spatial distribution of the highest melt fraction shows a distinctive linear trend roughly parallel to the western boundary of the North American plate (Figure 7a). Within the region of coverage, the drop in the melt volume fraction toward the NE at the edge of the stalled plate in the transition zone coincides with the decrease in thickness of the LVL, as shown in the cross section along the $\mathrm{A}-\mathrm{A}^{\prime}$ profile in Figure 5. The map of $\Delta V_{s}$, the melt fraction dependent wave speed anomaly as defined in equation (5), is plotted in Figure 7(b). The anticorrelation between the the melt volume fraction and $\Delta V_{s}$ is clear from visual comparison of the two maps in Figures 7(a) and (b). Histograms of the two quantities are shown in panel (c) annotating their median values. It is worth remembering that $\Delta V_{S}$, defined in equation (5), only isolates the anomaly associated with melting, 
as the effects of the temperature and bulk solid composition are incorporated in $V_{S}^{r e f}$.

The amplitude of P-S conversion shows an anticorrelation with the calculated melt volume fraction, with a Pearson correlation coefficient of -0.75 in figure $7(d)$. Such an anticorrelation is expected since the melt fraction is calculated from the amplitude of conversion and a higher magnitude of of conversion is likely to give rise to a higher melt volume fraction. The scatter, in this raw data, however, arises from variations in temperature between different stations. If the temperature at each location were the same, the data points in this plot would follow a smooth curve. This is shown in supplementary Figure 1(c), where these smooth curves are plotted for three different values of $\delta h$, the proxy for temperature. When the effect of temperature is removed, a smooth curve is also obtained for $\Delta V_{S}$, which isolates the effect of melting, as shown in Figure 7(e).

In the following section, we discuss the implications of our results for volatile transfer and storage in the mantle and the long term stability of the melt within the TZ.

\section{Discussion}

\subsection{How robust are seismic observations?}

An apparent LVL signal atop the 410-km discontinuity could result from various spurious signals on migrated CCP sections; (1) uncorrelated noise on raw and deconvolved seismograms, (2) sidelobes due to deconvolution, (3) interference of seismic phases, and (4) multiple reverberations within the uppermost mantle structure. While these issues are discussed in Tauzin et al. 
(2013), we present some key arguments below.

(1) With the high density US Transportable Array data, uncorrelated noise is not expected to give coherent signals over large-scale RF sections, and our uncertainty analysis from bootstrap resampling (section 2.1.2) clearly demonstrates that the LVL signal magnitude exceeds the noise level. (2) Sidelobes may be introduced by the deconvolution (Ligorria and Ammon, 1999) but are expected to be symmetric and on both sides of the main structural discontinuities. We demonstrated that these features appear neither on real nor on synthetic data (Tauzin et al., 2013). (3) In addition, our synthetic tests did not indicate any interference effects from seismic phases (such as PP or PcP) on the recovery of the CCP signal (Tauzin et al., 2013). (4) Reverberations in the shallow structure may be mistaken for direct conversions and wrongly interpreted as a true structure. Two reasons, however, indicate that it is not the case. First, to obtain flat converters, such as the LVL, requires flat and strong interfaces at shallow depths, which is unlikely given the present knowledge of the upper mantle structure in Western US. Second, at the scale of the western US, the precursory arrival to the P410s wave displays slowness similar to the conversion at the 410, (see Figure 2 in the supplementary material) demonstrating that this arrival is due to a true conversion at the top of the LVL.

\subsection{Source of volatiles}

Volatiles from the subducted Farallon plate must play an important role in melting in the LVL. We note that the temperature of the slab surface for both hot and cold slabs at depths of $350 \mathrm{~km}$ (Turcotte and Schubert, 2001) are colder than the solidus of mantle peridotite by $600-800 \mathrm{~K}$, as shown 
in Figure 8(a) and (b). To induce melting in the mantle at the observed depth, therefore, the presence of a volatile phase, namely $\mathrm{H}$ and/or $\mathrm{C}$ is crucial. While the seismic signal at such small melt fractions is insensitive to the melt composition (Hier-Majumder et al., 2014), a few indirect lines of evidence can point to the potential source of the melt (Figure 8(c)).

One evidence for melting induced by slab-derived $\mathrm{C}$ comes from a recent experimental study, suggesting that the carbonates in the subducting slab largely escapes devolatilization in the upper mantle leading to the generation of carbonatitic melt above the transition zone (Figure 8a; Thomson et al., 2016). In the strongly reducing mantle environment, however, the carbonatitic melt will rapidly react with the surrounding solids (Rohrbach and Schmidt, 2011), leaving behind a small amount of residual, unreacted melt. The small average melt volume fraction in our study is compatible with the signature of residual C-depleted melt resulting from such redox freezing in the mantle.

A second possible source of volatiles (Figure 8(c)) can arise from dehydration of high pressure mineral phase $\mathrm{E}$, a dense hydrous silicate mineral, in the transition zone (Ohtani et al., 2004). Coupled with mantle upwelling due to Yellowstone plume or small scale convection between the LVL and the slab, such dehydration can trigger melting, observed in the LVL (Bercovici and Karato, 2003; Richard and Bercovici, 2009). The observed small quantity of melt, in this scenario, is likely explained by a modest amount of $\mathrm{H}$ released upon dehydration, which reduces the solidus temperature modestly (Figure 8(b)). The small volume fraction of melt will remain bound to triple grain junctions in the matrix and will likely be advected with the matrix following 
the regional mantle flow pattern.

The melting zone reported here has a large storage capacity for volatiles. Considering a concentration of 1 to 10 wt $\%$ of $\mathrm{H}_{2} \mathrm{O}$ or $\mathrm{CO}_{2}$ in the melt, the melt layer underneath the Western US $\left(1.8 \times 10^{6} \mathrm{~km}^{2}\right.$ areal span and $40 \mathrm{~km}$ thick, density of $3500 \mathrm{~kg} / \mathrm{m}^{3}$ ) can store up to $1.2 \times 10^{16-17} \mathrm{~kg}$ of $\mathrm{H}_{2} \mathrm{O}$ or $\mathrm{CO}_{2}$ in the LVL. If the observed melt is a $\mathrm{CO}_{2}$ depleted residual melt from mantle metasomatism, then this estimate serves as a lower bound to the amount of $\mathrm{CO}_{2}$ that can be sequestered to the LVL upon melting. For example, a global LVL of similar thickness and $500 \mathrm{~km}$ width, associated with all subductions zones (global length of 37,000 km; Reymer and Schubert, 1984) and containing 1 vol\% carbonatitic melt (prior to redox freezing) with 50 wt $\% \mathrm{CO}_{2}$ (Thomson et al., 2016), can sequester $1.3 \times 10^{19} \mathrm{~kg}$ of $\mathrm{CO}_{2}$ in the upper mantle prior to metasomatism, a substantial portion of the mantle carbon reserve $\left(10^{19-20} \mathrm{~kg}\right.$; Dasgupta and Hirschmann, 2010). The presence of such a deep $\mathrm{CO}_{2}$ reservoir can explain the low $\mathrm{H}: \mathrm{C}$ ratio of the bulk silicate Earth compared to the surface abundances (Hirschmann and Dasgupta, 2009). While our results do not permit direct identification of the volatile species associated with the LVLs, they demonstrate that the melt in the LVL, owing to its large volatile storage capacity, can act as a larger global reservoir of volatiles than previously assumed.

\subsection{Stability of the melt within the LVL}

An important consideration following the generation of the melt is the retention of the melt in the source region. We argue that independent of the nature of the volatile species leading to melting, percolation of the observed small melt volume fraction will be inefficient for two reasons. First, volatile- 
rich melts should be nearly neutrally buoyant at the base of the upper mantle (Ghosh et al., 2007), reducing the primary driving force for percolation. Second, even in the presence of a density contrast between the melt and the matrix, mobility of the melt will be substantially reduced by the small melt fraction and low permeability, resulting in geologically significant residual time of the melt within the LVL (Hier-Majumder and Courtier, 2011).

To calculate the efficiency of percolation of residual melt out of the melting zone, we followed the analytical solution outlined by Hier-Majumder and Courtier (2011). In this model, we consider a 1-D melting column of constant melt volume fraction underneath each station location. The melt migration model assumes the matrix is motionless atop and at the bottom of the layer, isolating only density contrast-driven compaction within the layer. The velocity of melt and the matrix are coupled by conservation equations for mass and momentum (Bercovici et al., 2001). The analytical solution for the nondimensional velocity of the melt is given by,

$$
v_{m}^{\prime}=-\left[\frac{\left(1-\cosh z_{0}\right) \sinh z}{\sinh z_{0}}+\cosh z-1\right] \frac{3 R}{4} \phi_{0}\left(1-\phi_{0}\right)^{2},
$$

where $z$ is the nondimensional height of the column, $R$ is the dimensionless density contrast, $\phi_{0}$ is the melt volume fraction recorded at the location, and $z_{0}=1 / \sqrt{\phi_{0}\left(1-\phi_{0}\right)}$. We use a value of $R=0.05$ in arriving at the analytical solution, which represents a $5 \%$ density contrast between the melt and the matrix, compared to the density of the matrix. While petrological measurements indicate that volatile-rich silicate melts are likely to be neutrally buoyant at the base of the upper mantle (Ghosh et al., 2007), this calculation demonstrates even if the driving force was present, melt percolation will still be inefficient. Equation (8) indicates that the percolation velocity of the melt 
will be zero for a neutrally buoyant melt, for which $R=0$.

We dimensionalize the velocity in the melt column using the scheme,

$$
v_{m}=\frac{4 \rho_{m} g}{3 c} v_{m}^{\prime},
$$

where $\rho_{m}=3300 \mathrm{~kg} / \mathrm{m}^{3}$ is the matrix density, $g=10 \mathrm{~m} / \mathrm{s}^{2}$ is gravity, and the frictional resistance to melt percolation $\left(\mathrm{Pas} / \mathrm{m}^{2}\right)$ can be expressed as (Hier-Majumder, 2011)

$$
c=\mu_{f} \frac{72 \pi}{a^{2} \phi_{0}^{2}} .
$$

In equation (10), $\mu_{f}=1$ Pas is the viscosity of the melt and $a=1 \mathrm{~mm}$ is the grain size. To create the map of melt velocity in Figure 9, we take the maximum value of the absolute magnitude of velocity within the vertical column.

The dimensional permeability, $k$, at each point is given by the relation,

$$
k=\frac{\mu_{f}}{c} .
$$

The results for the melt percolation velocity and permeability at each location are shown in Figure 9. The mean velocity of the melt is $\sim 30 \mu \mathrm{m} / \mathrm{yr}$, indicating that it will take nearly $1 \mathrm{Ga}$ for melt to be completely extracted from a melt layer of $40 \mathrm{~km}$ thickness. In this calculation, we do not consider the effect of surface tension at grain boundaries, which will render melt extraction even more ineffective (Hier-Majumder et al., 2006). The time scale of $1 \mathrm{Ga}$ for melt stability in the LVL is similar to the estimated residence time for deep carbon (Hirschmann and Dasgupta, 2009), suggesting that the melting zone can act as a potential deep carbon reservoir. 


\section{Conclusion}

In summary, our results identify a pervasive LVL underneath the western US spanning over an area of $1.8 \times 10^{6} \mathrm{~km}^{2}$. The LVL shows significant variations in thickness in this region with some of the thickest regions associated with the coldest parts of the mantle. It also shows a clear spatial correlation with the stalled Farallon plate. The average melt content of the LVL is 0.5 $\pm 0.2 \mathrm{vol} \%$, with significant spatial variations. The sites with the strongest seismic anomaly register the highest melt volume fraction. These evidences suggest that melting induced by slab-derived volatile species plays a crucial role in the origin of the LVL.

\section{References}

Bercovici, D., Karato, S., 2003. Whole-mantle convection and the transition zone water filter. Nature 425, 39-44.

Bercovici, D., Ricard, Y., Schubert, G., 2001. A two-phase model for compaction and damage; 1, General theory. Journal of Geophysical Research, B, Solid Earth and Planets 106 (5), 8887-8906.

Bolfan-Casanova, N., 2002. Pressure dependence of H solubility in magnesiowüstite up to $25 \mathrm{GPa}$ : Implications for the storage of water in the Earth's lower mantle. Geophysical Research Letters 29 (10), 1-4. URL http://www .agu.org/pubs/crossref/2002/2001GL014457 . shtml

Bostock, M., 1999. Seismic waves converted from velocity gradient anomalies in the earth?s upper mantle. Geophysical Journal International 138 (3), $747-756$. 
Burdick, S., van der Hilst, R. D., Vernon, F. L., Martynov, V., Cox, T., Eakins, J., Karasu, G. H., Tylell, J., Astiz, L., Pavlis, G. L., 2010. Model update january 2010: Upper mantle heterogeneity beneath north america from traveltime tomography with global and usarray transportable array data. Seismological Research Letters 81 (5), 689-693.

Cerveny, V., 2005. Seismic ray theory. Cambridge university press.

Courtier, A. M., Jackson, M. G., Lawrence, J. F., Wang, Z., Lee, C.-T. A., Halama, R., Warren, J. M., Workman, R., Xu, W., Hirschmann, M. M., Larson, A. M., Hart, S. R., Lithgow-Bertelloni, C., Stixrude, L., Chen, W.-P., 2007. Correlation of seismic and petrologic thermometers suggests deep thermal anomalies beneath hotspots. Earth and Planetary Science Letters 264 (1-2), 308-316.

Courtier, A. M., Revenaugh, J., 2007. Deep upper-mantle melting beneath the tasman and coral seas detected with multiple scs reverberations. Earth and Planetary Science Letters 259, 66-76.

Dasgupta, R., Hirschmann, M. M., 2010. The deep carbon cycle and melting in Earth's interior. Earth Planet Sci. Lett 298, 1-13.

Dziewonski, A. M., Anderson, D. L., 1981. Preliminary reference earth model. Physics of the earth and planetary interiors 25 (4), 297-356.

Efron, B., Tibshirani, R., 1990. Statistical data analysis in the computer age. University of Toronto, Department of Statistics.

Fee, D., Dueker, K., 2004. Mantle transition zone topography and structure beneath the yellowstone hotspot. Geophysical Research Letters 31 (18). 
Gao, W., Matzel, E., Grand, S., 2006. Upper mantle seismic structure beneath eastern Mexico determind from $\mathrm{P}$ and $\mathrm{S}$ waveform inversion and its implications. J. Geophys. Res. 111, B08307.

Ghosh, S., Ohtani, E., Litasov, K., Suzuki, A., Sakamaki, T., NOV 222007. Stability of carbonated magmas at the base of the Earth's upper mantle. GEOPHYSICAL RESEARCH LETTERS 34 (22).

Hier-Majumder, S., 2011. Development of anisotropic mobility during twophase flow. Geophysical Journal International 186, 59-68.

Hier-Majumder, S., Courtier, A., 2011. Seismic signature of small melt fraction atop the transition zone. Earth and Planetary Science Letters 308 (34), 334-342.

Hier-Majumder, S., Keel, E., Courtier, A., 2014. The influence of temperature, bulk composition, and melting on the seismic signature of the low velocity layer above the transition zone. J. of Geophys. Res. Solid Earth 119.

Hier-Majumder, S., Ricard, Y., Bercovici, D., AUG 30 2006. Role of grain boundaries in magma migration and storage. Earth and Planetary Science Letters 248 (3-4), 735-749.

Hirschmann, M. M., oct 2000. Mantle solidus: Experimental constraints and the effects of peridotite composition. Geochemistry, Geophysics, Geosystems 1 (10).

URL http://www .agu.org/pubs/crossref/2000/2000GC000070.shtml 
Hirschmann, M. M., Dasgupta, R., May 2009. The H/C ratios of Earth's near-surface and deep reservoirs, and consequences for deep Earth volatile cycles. Chemical Geology 262 (1-2), 4-16.

URL http://linkinghub.elsevier.com/retrieve/pii/S0009254109000862

Hirschmann, M. M., Tenner, T., Aubaud, C., a.C. Withers, Sep. 2009. Dehydration melting of nominally anhydrous mantle: The primacy of partitioning. Physics of the Earth and Planetary Interiors 176 (1-2), 54-68. URL http://linkinghub.elsevier.com/retrieve/pii/S0031920109000673

Jasbinsek, J., Dueker, K., 2007. Ubiquitous low-velocity layer atop the 410km discontinuity in the northern Rocky Mountain. Geochem. Geophys. Geosys. 8, Q10004.

Jasbinsek, J. J., Dueker, K. G., Hansen, S. M., 2010. Characterizing the 410 $\mathrm{km}$ discontinuity low-velocity layer beneath the la ristra array in the north american southwest. Geochemistry, Geophysics, Geosystems 11 (3).

Kennett, B., Engdahl, E., 1991. Traveltimes for global earthquake location and phase identification. Geophysical Journal International 105 (2), 429465.

Kohlstedt, D., Keppler, H., Rubie, D., 1996. Solubility of water in the $\alpha, \beta$ and $\gamma$ phases of $(\mathrm{Mg}, \mathrm{Fe})_{2} \mathrm{SiO}_{4}$. Contributions to Mineralogy and Petrology $123,345-357$.

Ligorria, J. P., Ammon, C. J., 1999. Iterative deconvolution and receiverfunction estimation. Bulletin of the seismological Society of America 89 (5), 1395-1400. 
Liu, L., Stegman, D. R., 2011. Segmentation of the farallon slab. Earth and Planetary Science Letters 311 (1), 1-10.

Minarik, W., Watson, E. B., 1995. Interconnectivity of carbonate melt at low melt fraction. Earth Planet Sci. Lett. 133, 423-437.

Muller, G., 1985. The reflectivity method - a tutorial. Journal of GeophysicsZeitschrift Fur Geophysik 58 (1-3), 153-174.

Obrebski, M., Allen, R. M., Pollitz, F., Hung, S.-H., 2011. Lithosphereasthenosphere interaction beneath the western united states from the joint inversion of body-wave traveltimes and surface-wave phase velocities. Geophysical Journal International 185 (2), 1003-1021.

Ohtani, E., Litasov, K., Tomofumi, H., Kubo, T., Kondo, T., jun 2004. Water transport into the deep mantle and formation of a hydrous transition zone. Physics of The Earth and Planetary Interiors 143-144, 255-269. URL http://linkinghub.elsevier.com/retrieve/pii/S0031920104000603

Revenaugh, J., Sipkin, S., 1994. Seismic evidence for silicate melt atop the 410-km mantle discontinuity. Nature 369, 474-476.

Reymer, A., Schubert, G., 1984. Phanerozoic addition rates to the continental crust and crustal growth. Tectonics 3 (1), 63.

Richard, G. C., Bercovici, D., 2009. Water-induced convection in the Earth's mantle transition zone. Journal of Geophysical Research: Solid Earth $114(1), 1-11$. 
Rohrbach, A., Schmidt, M. W., 2011. Redox freezing and melting in the Earth's deep mantle resulting from carbon-iron redox coupling. Nature 472 (7342), 209-212.

URL http://dx.doi.org/10.1038/nature09899

Schmandt, B., Dueker, K. G., Hansen, S. M., Jasbinsek, J. J., Zhang, Z., 2011. A sporadic low-velocity layer atop the western U.S. mantle transition zone and short-wavelength variations in transition zone discontinuities. Geochemistry, Geophysics, Geosystems 12 (8).

Schmandt, B., Jacobsen, S. D., Becker, T. W., Liu, Z., Dueker, K., Dec. 2014. Dehydration melting at the top of the lower mantle. Science 344 (6189), $1265-1268$.

URL http://arxiv.org/abs/1312.4896

Song, T.-R. A., Helmberger, D. V., Grand, S. P., 2004. Low-velocity zone atop the 410-km seismic discontinuity in the northwestern united states. Nature 427 (6974), 530-533.

Tauzin, B., Debayle, E., Wittlinger, G., 2010. Seismic evidence for a global low-velocity layer within the Earth's upper mantle. Nature 3, 718-721, doi:10.1038/NGEO969.

Tauzin, B., Ricard, Y., 2014a. Seismically deduced thermodynamics phase diagrams for the mantle transition zone. Earth and Planetary Science Letters 401, 337-346.

URL http://dx.doi.org/10.1016/j.epsl.2014.05.039 
Tauzin, B., Ricard, Y., 2014b. Seismically deduced thermodynamics phase diagrams for the mantle transition zone. Earth and Planetary Science Letters 401, 337-346.

Tauzin, B., Van Der Hilst, R. D., Wittlinger, G., Ricard, Y., 2013. Multiple transition zone seismic discontinuities and low velocity layers below western united states. Journal of Geophysical Research: Solid Earth 118 (5), $2307-2322$.

Thomson, A. R., Walter, M. J., Kohn, S. C., Brooker, R. A., 2016. Extention: Slab melting as a barrier to deep carbon subduction. Nature 1 (2005), 1689-1699.

URL http://dx.doi.org/10.1038/nature16174

Turcotte, D., Schubert, G., 2001. Geodynamics. John Willey \& Sons.

Vinnik, L., Farra, V., 2007. Low S velocity atop the 410-km discontinuity and mantle plumes. Earth and Planetary Science Letters 262, 398-412, doi:10.1016/j.epsl.2007.07.051.

Vinnik, L., Ren, Y., Stutzmann, E., Farra, V., Kiselev, S., 2010. Observations of $\mathrm{s} 410 \mathrm{p}$ and $\mathrm{s} 350 \mathrm{p}$ phases at seismograph stations in california. Journal of Geophysical Research: Solid Earth 115 (B5).

von Bargen, N., Waff, H., 1986. Permeabilities, interfacial areas and curvatures of partially molten systems: results of numerical computations of equilibrium microstructures. Journal of Geophysical Research 91, 92619276. 
673

Wittlinger, G., Farra, V., 2007. Converted waves reveal a thick and layered tectosphere beneath the kalahari super-craton. Earth and Planetary Science Letters 254 (3), 404-415.

Wittlinger, G., Vergne, J., Tapponnier, P., Farra, V., Poupinet, G., Jiang, M., Su, H., Herquel, G., Paul, A., 2004. Teleseismic imaging of subducting lithosphere and moho offsets beneath western tibet. Earth and Planetary Science Letters 221 (1), 117-130.

Xu, W., Lithgow-Bertolini, C., Stixrude, L., Ritsema, J., 2008. The effect of bulk composition and temperature on mantle seismic structure. Earth Planet Sci. Lett. 275, 70-79.

\section{Acknowledgment}

SH-M acknowledges support from an NSF grant EAR 1215800. Insightful suggestions from two anonymous reviewers and Editor Peter Shearer greatly helped improve the revised version of the manuscript. 
(a)
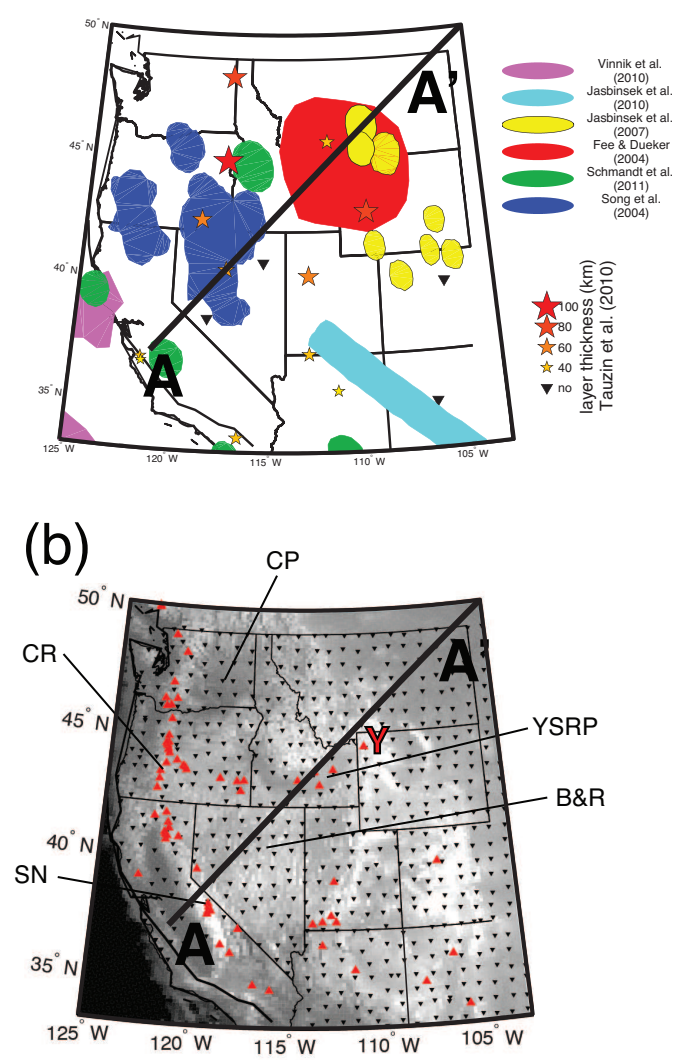

Figure 1: Low-velocity layer observations from dense seismic arrays. (a) A map summarizing previous observations of the LVLs across Western US. These observations have been obtained from several independent studies using small-aperture seismic networks. (b) The larger-aperture seismic network used in this study is the Transportable Array (black triangles), covering the western half of the US with an average station spacing of $70 \mathrm{~km}$. The Caltech Regional Seismic Network has not been processed, explaining a gap in coverage in the extreme South of California. The seismic profile discussed in this study is labeled A-A' and marked with a black line. Important physiographic features of the western US are labeled, such as the Cascadia ranges (CR), the Yellowstone Snake River plain (YSRP), the Yellowstone caldera (Y), the Columbia plateau (CP), the Sierra Nevada (SN), and the Basin and Range province (B\&R). Major Quaternary active volcanoes (red triangles) are either arc-related, due to the present subduction of the Juan de Fuca plate below the Cascadia ranges, or possibly hotspot-related in the Snake River Plain and Yellowstone regions. 
(a)

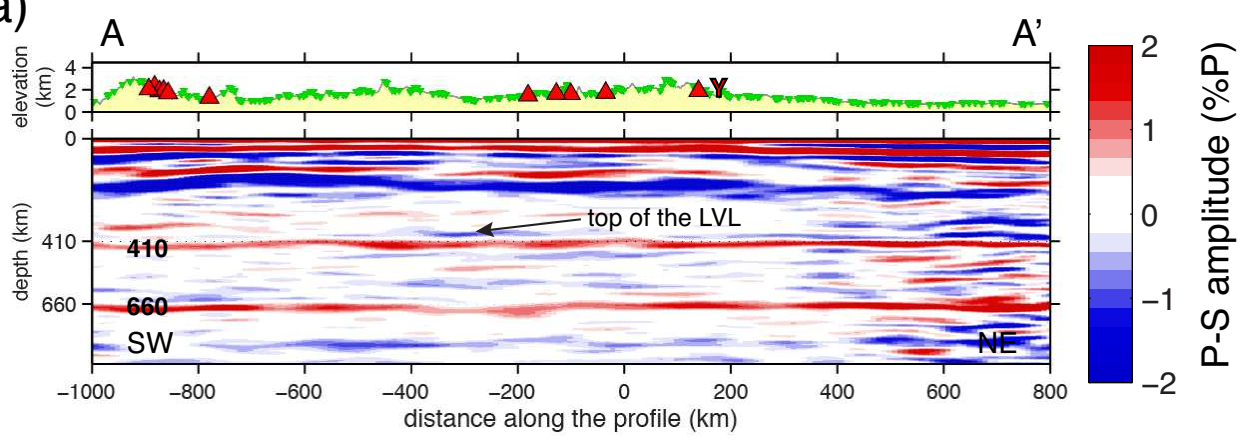

(b)

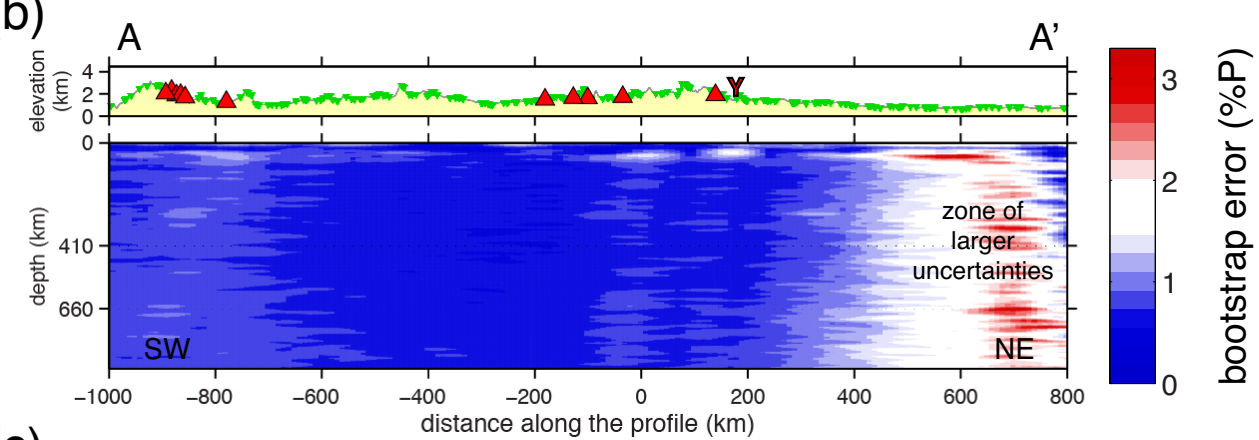

(c)

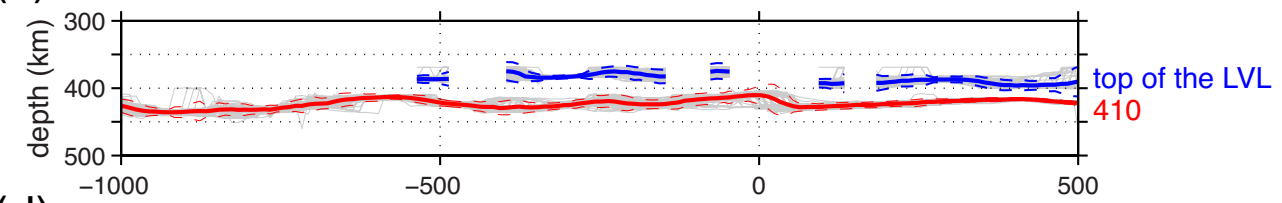

(d)

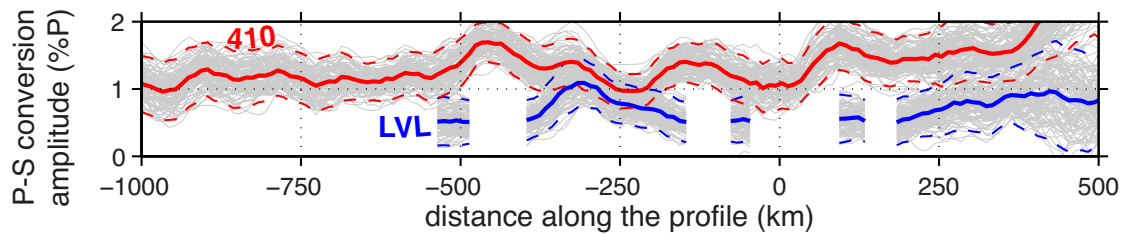

Figure 2: The result of applying common conversion point stacking and bootstrap resampling on the RFs of the A-A' profile. (a) The average seismic section. (b) One standard deviation giving the $65 \%$ confidence level on seismic amplitudes. A robust interpretation can be conducted up to $+500 \mathrm{~km}$ along the profile. (c) The result of bootstrap resampling for the depth of the 410-km discontinuity and the top of the LVL with the $N=50$ samples (gray lines), the averages (blue and red solid lines), and the 95\% confidence levels (blue and red dashed lines). (d) Same as (c) except that we analyze the P-S conversion amplitudes at the $410-\mathrm{km}$ discontinuity and at the top of the LVL. 
(a) TZ thickness variation

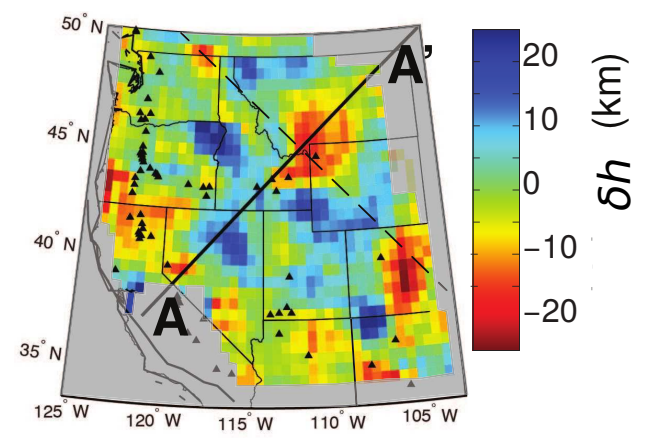

(b) Tomography

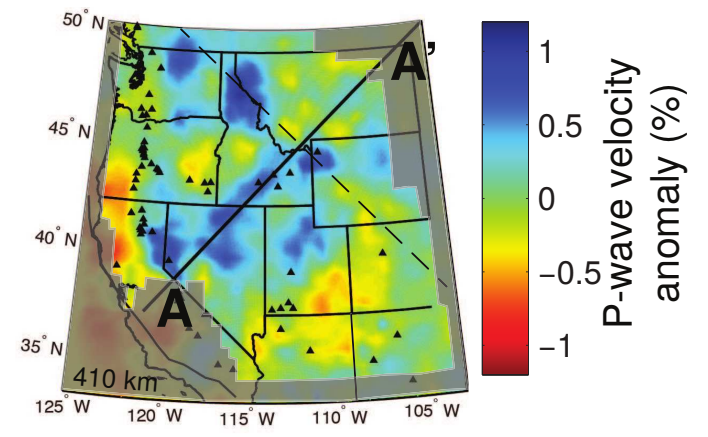

Figure 3: The transition zone structure. (a) An estimate of the variation in transition zone thickness below the seismic array (Tauzin et al., 2013). (b) A cross-section at $410 \mathrm{~km}$ depth through the P-wave tomographic model of Burdick et al. (2010). The area that is not covered by the seismic array is shaded in gray. The black dashed line that is roughly parallel to the coastline delimits distinctive patterns of thickened TZ and fast velocity anomalies from other regions of normal mantle in the northeast. 

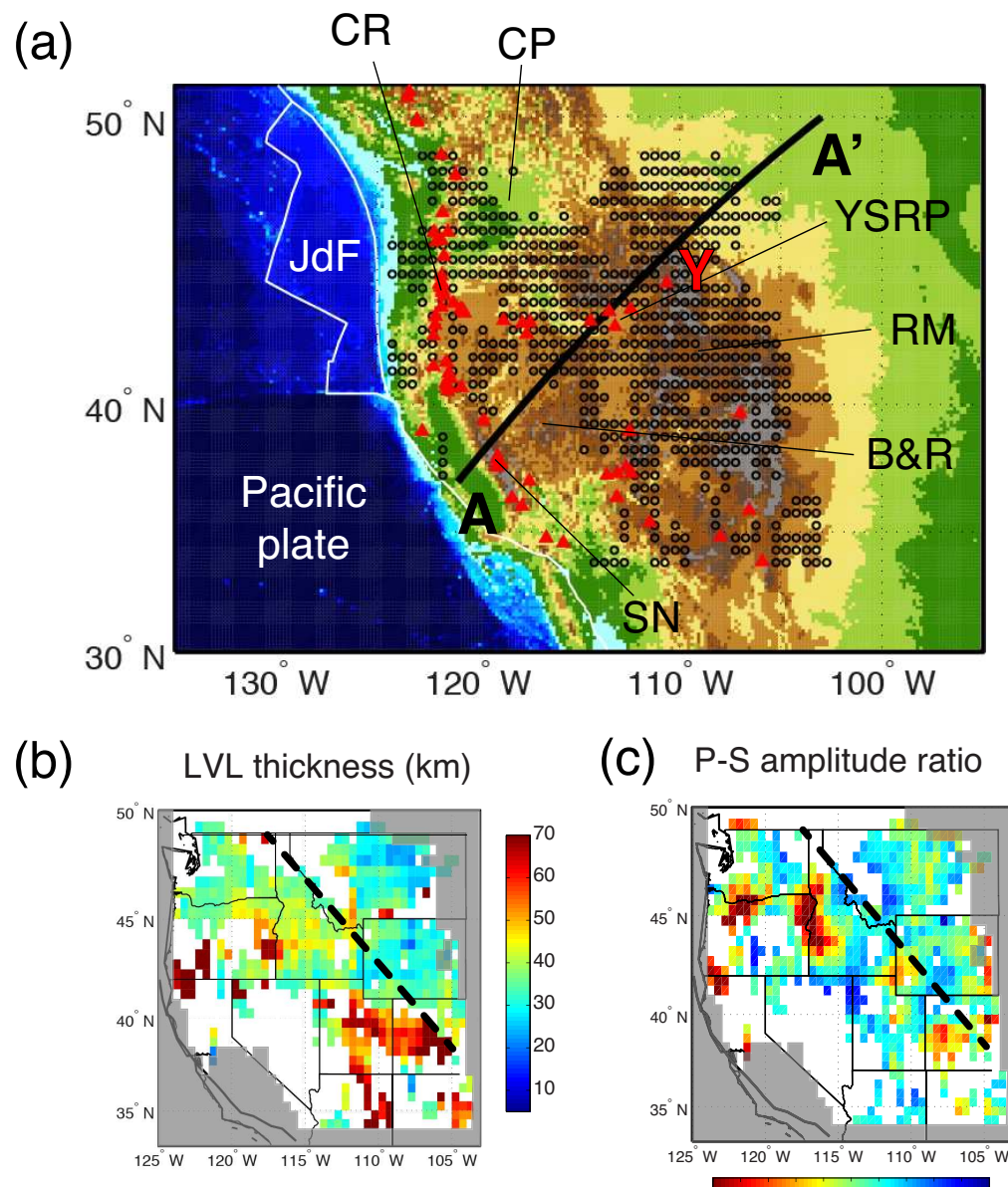

(C) P-S amplitude ratio

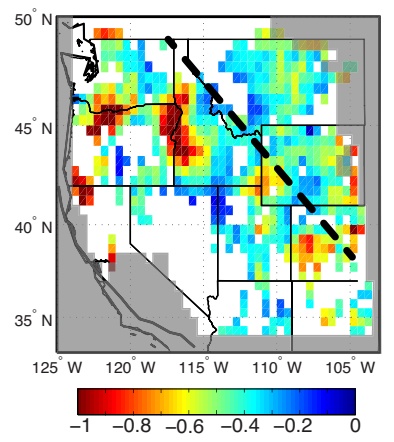

Figure 4: The 350-km deep low-velocity layer below the western US. (a) The LVL (black dots) spreads out across most part of the region, including the topographic highs of the Cascadia ranges (CR), the Rocky Mountains (RM) and the Yellowstone caldera (Y), but also the topographic lows of the Yellowstone Snake River plain (YSRP) and Columbia plateau $(\mathrm{CP})$. At the southwest, the LVL is absent below the Sierra Nevada (SN) and the Basin and Range province (B\&R). Major Quaternary active volcanoes are indicated with red triangles. The seismic structure along the $\mathrm{A}-\mathrm{A}^{\prime}$ profile is described in detail in Figure 5. (b) A map of the lateral variations of the LVL thickness. (c) Map of the ratio of the amplitude of the P-S conversion at the LVL relative to the 410. In bottom panels, the area with no seismic data coverage is shaded in gray. The black dashed line that is roughly parallel to the coastline delimits distinctive patterns of thick LVL and high-amplitude of conversion at the uppermost interface of the $35 \mathrm{EL}$, from other regions of thinner LVL and lower amplitude of conversion in the northeast. 
(a)
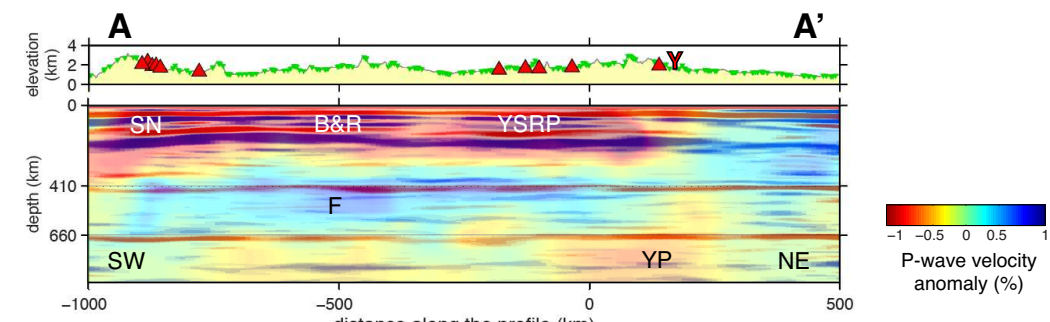

(b)

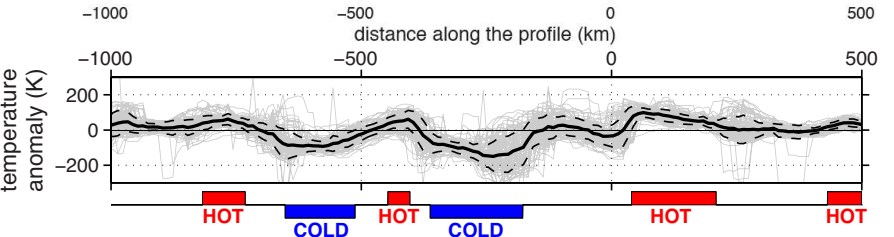

(c)

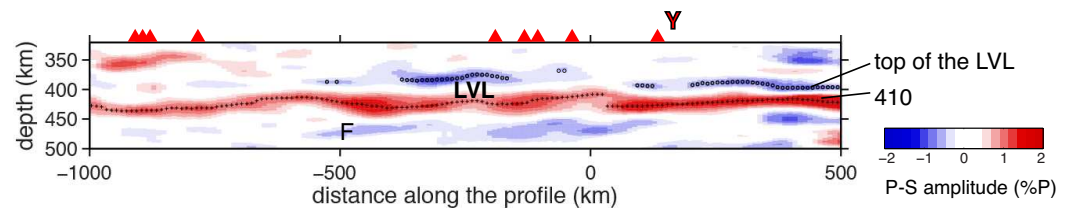

(d)

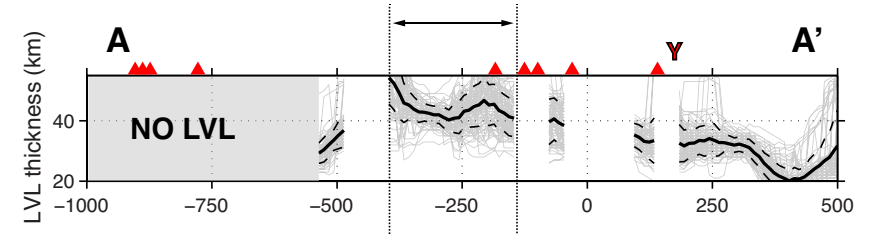

(e)

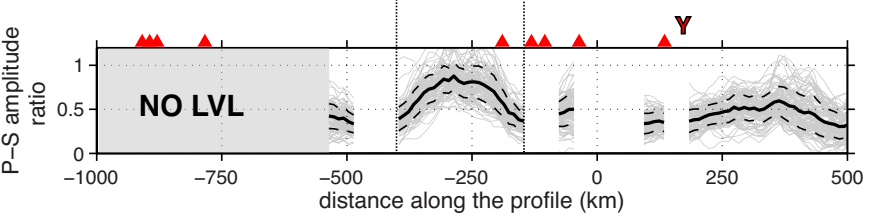

Figure 5: The seismic structure of the LVL. (a) The superimposition of a cross-section through the P-wave tomographic model of (Burdick et al., 2010) on our RF seismic section along the A-A' profile indicates that the slow regions are mostly located in the uppermost part of the mantle, below the Sierra Nevada (SN), the Basin and Range (B\&R), and the Yellowstone Snake River plain (YSRP). An elongated fast velocity body represents a fragment of the Farallon plate (F), stalled within the transition zone. In the northeast, at the top of the lower mantle, a slow velocity anomaly has been interpreted as the Yellowstone plume (YP) (Obrebski et al., 2011), piercing through the transition zone, and reaching the Yellowstone Caldera in surface ( $\mathrm{Y}$ on the topographic profile). (b) Measured temperature anomalies indicate a succession of hot (red) and cold (blue) thermal regimes in the transition zone. (c) A zoom over our RF seismic section depicts the fine structure of the LVL atop the 410-km discontinuity. Negative ${ }^{6}$ amplitudes (blue) mark a shear-wave velocity decrease, such as atop the LVL, whereas positive amplitudes (red) mark a shear-wave velocity increase, such as at the 410 discontinuity. (d) The LVL is the thickest at the western side of the YSRP and gradually decreases toward the Yellowstone region. (e) P-S conversion amplitudes at the LVL follow roughly the same trend. 


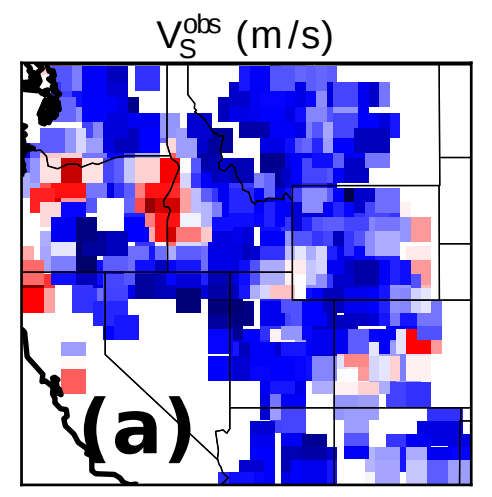

4725

4700

4675

4650

4625

4600

4575

4550

4525

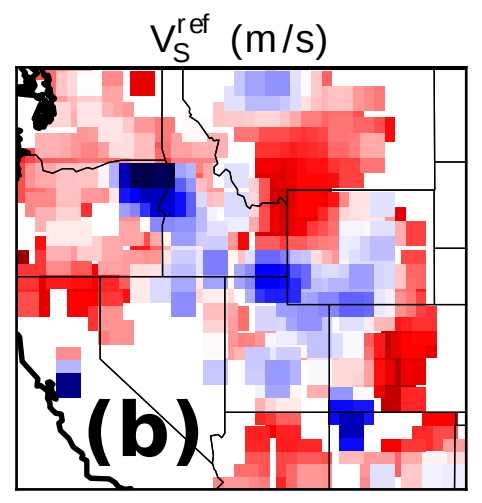

4890

4860

4830

4800

4770

4740

4710

4680

4650

Figure 6: (a) Map of the observed seismic wave speed, $V_{S}^{o b s}$, calculated from the amplitude of P-S conversion using equations (2). (b) Map of the reference shear wave speed from the model of Xu et al. (2008), for a reference mantle potential temperature of $1600 \mathrm{~K}$ and a bulk peridotite composition containing $40 \%$ basaltic component. The lateral variation in $V_{S}^{\text {ref }}$ is caused by variation in temperature calculate from the variations in transition zone thickness as shown in Figure 3(a). 

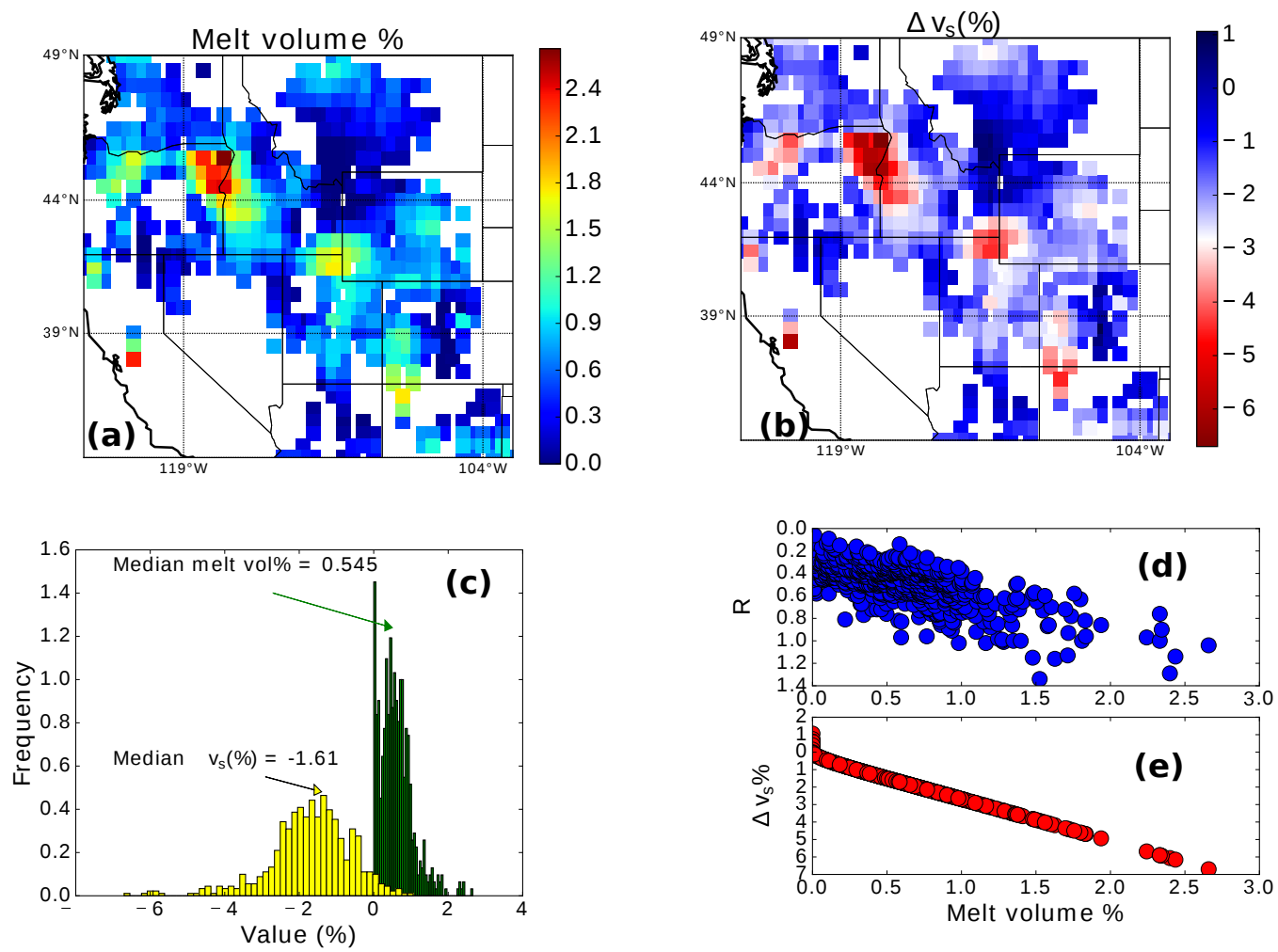

Figure 7: (a) Map of the melt volume \% derived at the 583 sites of observation of the LVL. In all panels, the reference mantle temperature is $1600 \mathrm{~K}$, the Clapeyron slope of olivine-Wadsleyite transition is $+3 \mathrm{MPa} / \mathrm{K}$ and the melt dihedral angle is $25^{\circ}$. (b) Map of $\Delta V_{S}$ in $\%$ values. (c) Histogram of melt volume $\%$ and $\Delta V_{S}$ from the maps in panel (a) and (b). The median value of each variable is annotated in the plot. (d) Plot of the normalized amplitude of P-S conversion as a function of calculated melt volume \%. The Pearson correlation coefficient of the data points is -0.75. (e) Plot of $\Delta V_{S}$ as a function of melt volume fraction. 


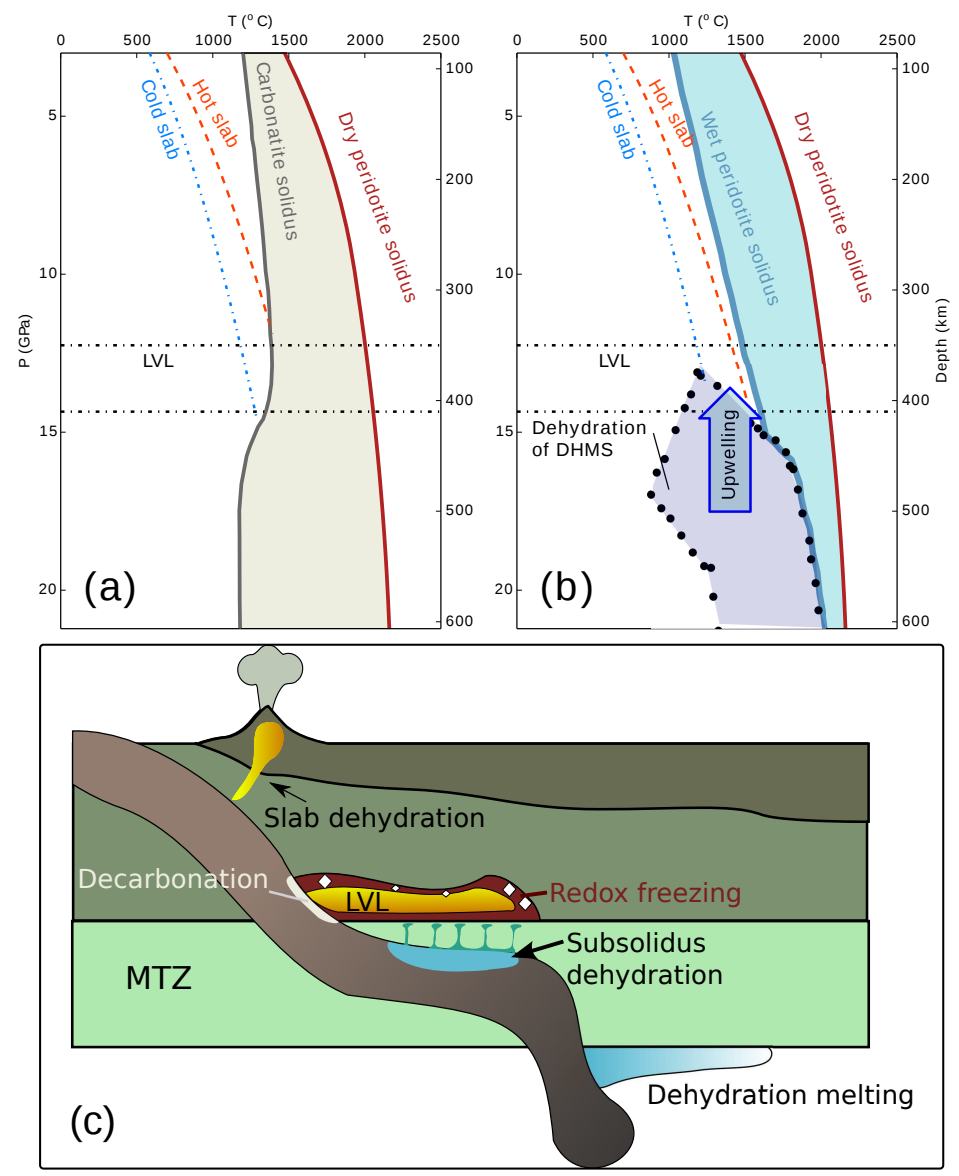

Figure 8: Plots of peridotite solidi and key reactions. In both plots the dry peridotite solidus is constructed from Hirschmann (2000) for pressures less than $10 \mathrm{GPa}$ and Hirschmann et al. (2009) for pressures above $10 \mathrm{GPa}$. The slab geotherms were calculated for subduction velocities of 10 (cold) and 7 hot $\mathrm{cm} / \mathrm{yr}$, respectively (Turcotte and Schubert, 2001, Ch. 4-29). The carbonatite solidus in panel (a) is taken from Thomson et al. (2016). The wet peridotite solidus and the dehydration of dense hydrous magnesium silicate (DHMS) fields are taken from Ohtani et al. (2004). This cartoon outlines a few possible hypotheses on devolatilization reactions and their consequences in and around the transition zone. The observed melt in the LVL can arise from decarbonation melting atop the transition zone (Thomson et al., 2016) or subsolidus dehydration of dense hydrous silicate minerals followed by small scale convection above the stalled slab (Ohtani et al., 2004; Richard and Bercovici, 2009). In the small scale convection model, the small plumes are melt-free, hydrated, low-viscosity, low-density aggregates of solid. In the first model, a redox freezing zone (Rohrbach and Schmidt, 2011), which may not be seismically visible, should surround small amounts of residual melt. Dehydration of hydrous ringwoodite, dragged along the slab triggers dehydration melting beneath the transition zone (Schmandt et al., 2014). 


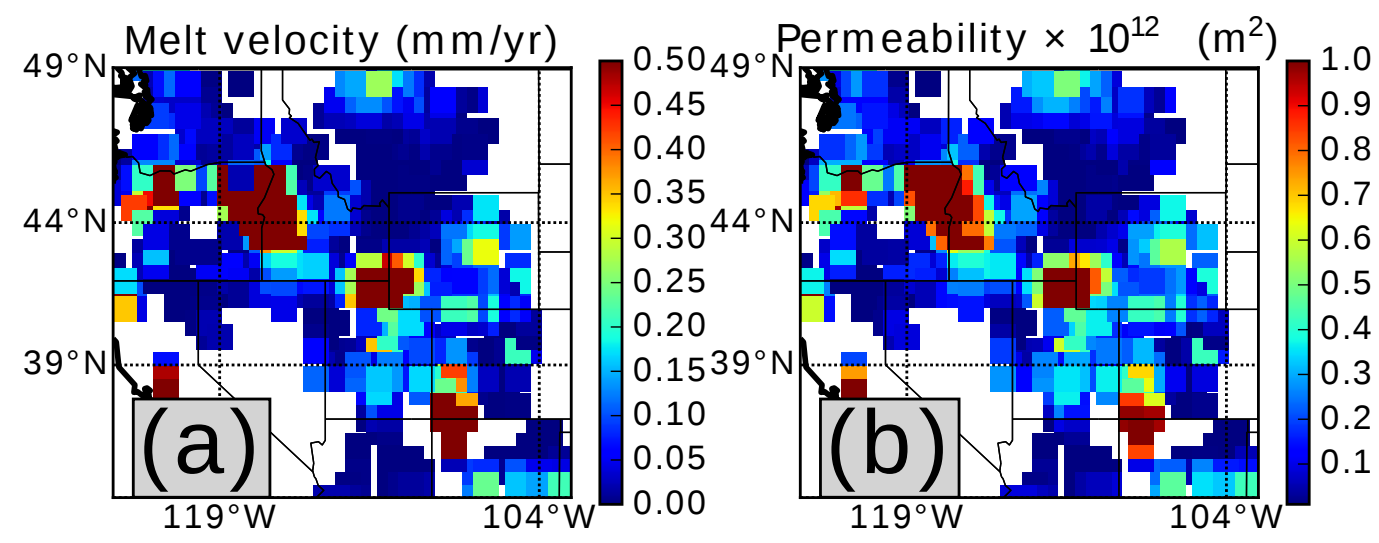

Figure 9: Results from the melt migration calculation. (a) A map of melt percolation velocity at each site. The velocity at each site represents the maximum velocity in a column described by equation 8. (b) A map of permeability at each point calculated using the melt fraction determined from the P-S receiver function analysis. 